\title{
Mechanisms of the harmful effects of bacterial semen infection on ejaculated human spermatozoa: potential inflammatory markers in semen
}

\author{
Monika Fraczek, Maciej Kurpisz
}

Department of Reproductive Biology and Stem Cells, Institute of Human Genetics Polish Academy of Sciences, Poznan, Poland

\begin{abstract}
The invasion of the male reproductive tract by microorganisms, and its subsequent consequences for sperm fertilizing potential, has been intensely discussed. The role of the bacteria that are responsible for the colonization and contamination of the male urogenital tract, rather than its infection, in diminished sperm parameters raises the most controversy. There are numerous premises suggesting that bacterial semen infection is associated with male infertility. However, the molecular mechanism by which the fertility is affected is complex and multifactorial, and still presents a puzzle. Some authors have suggested that direct interactions between bacteria and human spermatozoa facilitate sperm immobilization, affect sperm morphology, and thus weaken the ability of sperm to fertilize. On the other hand, the massive infiltration of activated leukocytes into the inflammatory site may be associated with impairment of sperm fertilizing potential, due to oxidative, apoptotic, and immune processes. This review presents current research trends and aims to summarize the present knowledge of semen inflammation and causative bacterial agents in the male urogenital tract, with its consequence on seminological parameters, and male fertility status. (Folia Histochemica et Cytobiologica 2015, Vol. 53, No. 3, 201-217)
\end{abstract}

Key words: bacterial semen infection; sperm quality; oxidative stress; sperm apoptosis

\section{Introduction}

Urogenital tract inflammations and infections are thought to be responsible for up to $15 \%$ of cases of male infertility. According to clinical data, as many as $60 \%$ of patients treated with assisted reproductive technology (ART) had suffered local inflammation or infection. The direct relationship between acute or chronic inflammations and infections of the male urogenital tract and the subsequent development of infertility is actively debated, and constitutes an important problem in contemporary andrology. Due to the anatomical topography, local inflammations and infections include chronic urethritis, orchitis,

\footnotetext{
Correspondence address: M. Kurpisz, M.D., Ph.D.

Institute for Human Genetics

Polish Academy of Sciences

Strzeszynska St. 32, 60-479 Poznan

tel.: +486165792 02/12, fax: +48618233235

e-mail: kurpimac@man.poznan.pl
}

epididymitis, prostatitis, vesiculitis, and obstruction of the seminal tract. However, these rarely occur in only one gland, which complicates their diagnosis and proper treatment. The course of the inflammatory process and its detrimental effect on sperm depends on the type of the initiating factor, the type and activation of infiltrating leukocytes, the duration of contact of spermatozoa with inflammatory mediators, and the genetic predisposition to the inflammatory response [1]. The majority of inflammatory disorders within the male genital tract are of infectious origin. The bacteria, viruses, Chlamydiae, and fungi responsible for semen infection may originate from the urinary tract or may be sexually transmitted; their role in causing male infertility has been discussed in recent years. However, the role of different types of bacteria that colonize and contaminate the male urogenital tract in diminishing sperm parameters is the issue that raises the most controversy. The clinical and experimental data suggest that bacteriospermia and leukocytospermia may inhibit male fertility by affecting the 
sperm characteristics directly or indirectly by acting on the regulatory systems. The purpose of this review is an attempt to summarize the current knowledge of the main pathophysiological concepts describing the harmful effects of bacterial semen infection on sperm cells.

\section{Direct effect of bacteria and leukocytes on sperm quality}

There are many reports demonstrating that bacterial invasion could contribute to sperm quality deterioration that is visible in routine semen analysis, especially in infertile men (Table 1) [2-31]. Decreasing sperm concentration, loss of motility, sperm morphological alterations, and impairment of acrosome reactions are the most frequent alterations revealed in spermatozoa attributable to bacteria in both in vivo and in vitro conditions. Most data concern well-known causative agents of urogenital tract infections, such as Escherichia (E.) coli, Staphylococcus (S.) aureus, Enterococcus (E.) faecalis, Ureaplasma (U.) urealyticum, Mycoplasma (M.) hominis, and Chlamydia (C.) trachomatis. However, some authors have suggested that other bacteria, responsible for the colonization and contamination of the male urogenital tract, rather than infection, could also contribute to the decrease in sperm quality $[32,33]$. During bacterial semen infection, sperm motility and normal morphology loss may be consequences of adhesion phenomena and sperm agglutination. The sperm surface is rich in glycoproteins and is thus susceptible to bacteriaspermatozoa interactions at the receptor-ligand level $[34,35]$. The tight adhesion between bacteria and male gametes was found for E. coli, C. trachomatis, T-mycoplasma, and $U$. urealyticum $[10,24,36]$. Interestingly, in our morphological in vitro study, the adhesion of Staphylococcus (S.) haemolyticus and Bacteroides (B.) ureolyticus (bacteria of questionable clinical significance) to the apical part of the acrosome and to the flagellum of spermatozoa have also been revealed (Figure 1) [10]. In particular, E. coli strains are known for their ability to immobilize and damage the morphology of spermatozoa by direct contact, mediated by attachment organelles such as pili or type-1 fimbriae (projections) and mannose receptor-dependent interactions. Another type of adhesins, namely $\mathrm{P}$ fimbriae, are important and widely studied mannose-resistant adhesion molecules present in 40-60\% of uropathogenic (UPEC) isolates [37]. High incidences of P-fimbriated E. coli strains have been found in acute prostatitis [38]. Our experience with P-fimbriated $E$. coli serotype O75:HNT has confirmed direct contact adhesion to the surface of sperm midpiece, principal piece, and acrosome, mediated by projections and sperm agglutination, and resulting in ultrastructural alterations in regions with attached bacteria (Figure 1) [39]. It should be emphasized that despite the ultrastructural evidences observed in both in vitro and in vivo conditions, there is no general consensus on a negative relevance of the bacteriospermia on sperm morphology parameters, assessed as a part of the routine sperm analysis. On the one hand, some authors demonstrated poor sperm morphology characteristics in the presence of several types of bacteria (Table 1). Also, the improvement in sperm parameters including sperm morphology abnormalities in men with urogenital tract infections after long-term antibiotic treatment has been observed [40]. On the other hand, sperm morphology alterations associated with elongation and reduced acrosomal inducibility have been found in men with inflammatory chronic prostatitis/chronic pelvic pain syndrome, and these changes were attributed rather to leukocytes [41]. There is an ongoing discussion whether chronic epididymitis additionally induces inflammatory semen alterations, especially sperm morphology abnormalities such as 'tapering' of sperm heads and differences in tail colouring [42]. Taking into consideration the fact that the increased sperm head length is usually accompanied by the sperm nuclear anomalies, factors other than conventional semen parameters can be a major issue to diagnose urogenital tract infections/inflammations. In this context, the assessment of DNA integrity can provide more information about the underlying pathophysiological mechanism of infertility [43]. This will be discussed in details later in this review.

The harmful effects of numerous microbial pathogens on spermatozoa not only result from the tight adhesion of interacting cells, but also from the expression of other surface virulent factors, such as lipopolysaccharides (LPS), cytotoxic necrotizing factor, $\alpha$-haemolysins, $\beta$-haemolysins, and from the release of soluble spermatotoxic factors such as sperm immobilization factor (SIF) [37, 44]. For example, E. coli haemolysins might be involved in the molecular mechanism that ultimately alters the membrane integrity [45]. In turn, SIF can inhibit sperm motility and viability by decreasing mitochondrial ATPase activity [35]. However, a loss of sperm motility concomitant with the integrity of the sperm mitochondrial membrane potential $(\Delta \psi \mathrm{m})$ during experimental in vitro semen infection has also been reported in the presence of bacteria that do not produce SIF, such as known pathogenic C. trachomatis [15] and the conditionally pathogenic $S$. haemolyticus and $B$. ureolyticus $[9,10]$. Most probably, a complex balance between 
Table 1. Effects of individual bacterial strains on sperm quality including conventional as well as nonconventional seminal parameters demonstrated in both in vivo and in vitro conditions

\begin{tabular}{|c|c|c|}
\hline Bacterial strain & Consequences on semen quality & References \\
\hline Escherichia coli & $\begin{array}{l}\downarrow \text { sperm count } \\
\downarrow \text { sperm motility } \\
\downarrow \text { sperm morphology } \\
\downarrow \text { sperm motility (in vitro) } \\
\downarrow \text { sperm viability (in vitro) } \\
\uparrow \text { MDA (in vitro) } \\
\downarrow \Delta \text { Ym } \\
\uparrow \text { mitochondrial ROS } \\
\uparrow \text { PS externalization (in vitro) } \\
\downarrow \text { acrosome reaction (in vitro) }\end{array}$ & $\begin{array}{l}2] \\
{[2,3]} \\
{[3]} \\
{[4-9]} \\
{[7,9]} \\
{[8,9]} \\
{[7,8,10]} \\
{[8]} \\
{[11]} \\
{[5,12]}\end{array}$ \\
\hline Chlamydia trachomatis & $\begin{array}{l}\downarrow \text { sperm count } \\
\downarrow \text { sperm progressive motility } \\
\downarrow \text { sperm motility } \\
\downarrow \text { sperm morphology } \\
\uparrow \text { MDA } \\
\downarrow \Delta \Psi \mathrm{m} \\
\uparrow \text { PS externalization (in vitro) } \\
\uparrow \text { DNA fragmentation } \\
\uparrow \text { DNA fragmentation (in vitro) }\end{array}$ & $\begin{array}{l}{[13-15]} \\
{[15,16]} \\
{[13]} \\
{[13]} \\
{[17]} \\
{[15]} \\
{[18]} \\
{[15,19]} \\
{[18]}\end{array}$ \\
\hline Ureaplasma urealyticum & $\begin{array}{l}\downarrow \text { sperm count } \\
\downarrow \text { sperm motility } \\
\downarrow \text { sperm morphology } \\
\downarrow \text { sperm viability } \\
\downarrow \text { sperm motility (in vitro) } \\
\downarrow \text { sperm morphology (in vitro) } \\
\downarrow \text { viability (in vitro) } \\
\downarrow \text { pH value } \\
\uparrow \text { viscosity } \\
\uparrow \text { ROS }\end{array}$ & $\begin{array}{l}{[2,20-22]} \\
{[2,21,23]} \\
{[21]} \\
{[2,22,23]} \\
{[24,25]} \\
{[24]} \\
{[24,25]} \\
{[20]} \\
{[20]} \\
{[26]}\end{array}$ \\
\hline Mycoplasma hominis & $\begin{array}{l}\downarrow \downarrow \text { sperm count } \\
\downarrow \text { sperm motility } \\
\downarrow \text { sperm morphology } \\
\downarrow \text { sperm motility (in vitro) } \\
\downarrow \text { acrosome reaction (in vitro) }\end{array}$ & $\begin{array}{l}27] \\
{[23]} \\
{[27]} \\
{[5]} \\
{[5]} \\
\end{array}$ \\
\hline Mycoplasma genitalium & $\downarrow$ sperm count & [27] \\
\hline Enterococcus faecalis & $\begin{array}{l}\downarrow \text { sperm count } \\
\downarrow \text { sperm morphology }\end{array}$ & $\begin{array}{l}{[28]} \\
{[28,29]}\end{array}$ \\
\hline Staphylococcus aureus & $\begin{array}{l}\text { sperm count } \\
\downarrow \text { sperm motility } \\
\downarrow \text { sperm morphology } \\
\uparrow \text { PS externalization (in vitro) }\end{array}$ & $\begin{array}{l}{[2]} \\
{[2,3]} \\
{[2,3]} \\
{[11]}\end{array}$ \\
\hline Pseudomonas aeruginosa & $\downarrow$ sperm progressive motility (in vitro) & {$[4]$} \\
\hline Bacteroides ureolyticus & $\begin{array}{l}\downarrow \text { morphology } \\
\downarrow \text { sperm motility (in vitro) } \\
\downarrow \text { sperm viability (in vitro) } \\
\uparrow \mathrm{MDA} \text { (in vitro) } \\
\downarrow \Delta \Psi \mathrm{M} \text { (in vitro) } \\
\uparrow \mathrm{PS} \text { externalization (in vitro) } \\
\uparrow \mathrm{DNA} \text { fragmentation (in vitro) }\end{array}$ & $\begin{array}{l}{[30]} \\
{[9]} \\
{[9,10]} \\
{[9]} \\
{[10]} \\
{[31]} \\
{[31]}\end{array}$ \\
\hline
\end{tabular}


Table 1 (cont.). Effects of individual bacterial strains and sperm quality including conventional as well as nonconventional seminal parameters demonstrated in both in vivo and in vitro conditions

\begin{tabular}{|l|l|l|}
\hline Streptococcus viridans & $\downarrow$ sperm count & {$[29]$} \\
& $\downarrow$ sperm morphology & {$[29]$} \\
\hline Staphylococcus haemolyticus & $\downarrow$ sperm motility (in vitro) & {$[9]$} \\
& $\downarrow$ sperm viability (in vitro) & {$[9,10]$} \\
& $\uparrow$ MDA (in vitro) & {$[9]$} \\
& $\downarrow \Delta \Psi \mathrm{m}$ (in vitro) & {$[10]$} \\
& $\uparrow$ PS externalization (in vitro) & {$[31]$} \\
& $\uparrow$ DNA fragmentation (in vitro) & {$[31]$} \\
\hline Staphylococcus saprophyticus & $\downarrow$ motility & {$[3]$} \\
& $\downarrow$ sperm morphology & {$[3]$} \\
\hline Gardnerella vaginalis & $\downarrow$ concentration & {$[21]$} \\
& $\downarrow$ motility & {$[21]$} \\
& $\downarrow$ morphology & {$[21]$} \\
\hline
\end{tabular}

the expression of virulent factors in different types of bacteria and the host defence status marks a thin borderline between semen contamination/colonization and infection, especially in the context of bacteria that have so far been considered 'nonpathogenic' to sperm cells. The establishment of a minimal threshold for particular bacterial strains seems to be essential in evaluating their negative influence on sperm quality with real consequences for fertilization potential and the decision to take targeted therapy.

Infectious factors trigger the infiltration of leukocytes to the inflammatory site. Peroxidase-positive leukocyte concentration in excess of $1 \times 10^{6} \mathrm{~mL}^{-1}$ ejaculate, a condition called leukocytospermia, is generally attributed to the inflammation or infection of semen [46]. However, some authors have postulated the necessity to reevaluate this threshold [47-50]. According to the kinetics of the inflammatory process in the urogenital tract previously proposed by our group, leukocytes appear in semen as the addition to bacteriospermia at the second stage of the urogenital tract infection, and remain present in semen for some length of time following the elimination of the bacteria in the third stage (isolated leukocytospermia) [51]. There is an ongoing controversy concerning the biological role of the leukocytes attracted into the semen. Some authors have indicated a lack of any connection between leukocytospermia and diminished semen quality [52-54]. However, the vast majority of clinical and experimental in vitro reports have shown a direct association between leukocytospermia and deterioration in semen parameters, in terms of total sperm count [55, 56], sperm motility [9, 55, 57-60], sperm morphology $[56,59,60]$, and sperm viability [60]. Moreover, according to some authors, leukocytospermia represents an essential or additional risk factor that needs to be treated if sperm quality is to be improved [61, 62]. On the other hand, the observed alterations of standard sperm parameters accompanying leukocytospermia have not always been associated with a decreased fertilizing ability of the sperm, especially in assisted conception procedures $[63,64]$. These data are indirectly in agreement with the results that we obtained in an in vitro model of semen bacterial infection, indicating the detrimental effect of leukocytes alone on sperm motility and the hypoosmotic swelling (HOS) test. However, the decrease in sperm function reflected in the sperm penetration assay (SPA) was visible when leukocytes were used together with bacteria [9].

Almost $90 \%$ of the leukocytes attracted into semen during bacterial semen infection are phagocytic cells such as polymorphonuclear granulocytes (PMN) and macrophages. To date, little is known about direct associations between the presence of macrophages in semen and male subfertility or infertility, mainly due to the fact that the establishment of this second abundant leukocyte subpopulation within semen is not a part of the routine peroxidative test recommended by the World Health Organization [46]. However, some authors have suggested that activated macrophages are frequently observed in nonleukocytospermic infertile men and that they may be associated with altered sperm parameters $[49,65,66]$. The tight adhesion of both leukocyte types, neutrophils, and macrophages to the surface of the sperm results in phagocytic process (Figure 1). Interestingly, our morphological ultrastructural findings have revealed, for the first time, that the immobilization of human spermatozoa by activated leukocytes may be mediated by three different mechanisms: by direct cell-to-cell attachment, by leukocytic processes at the early stage 


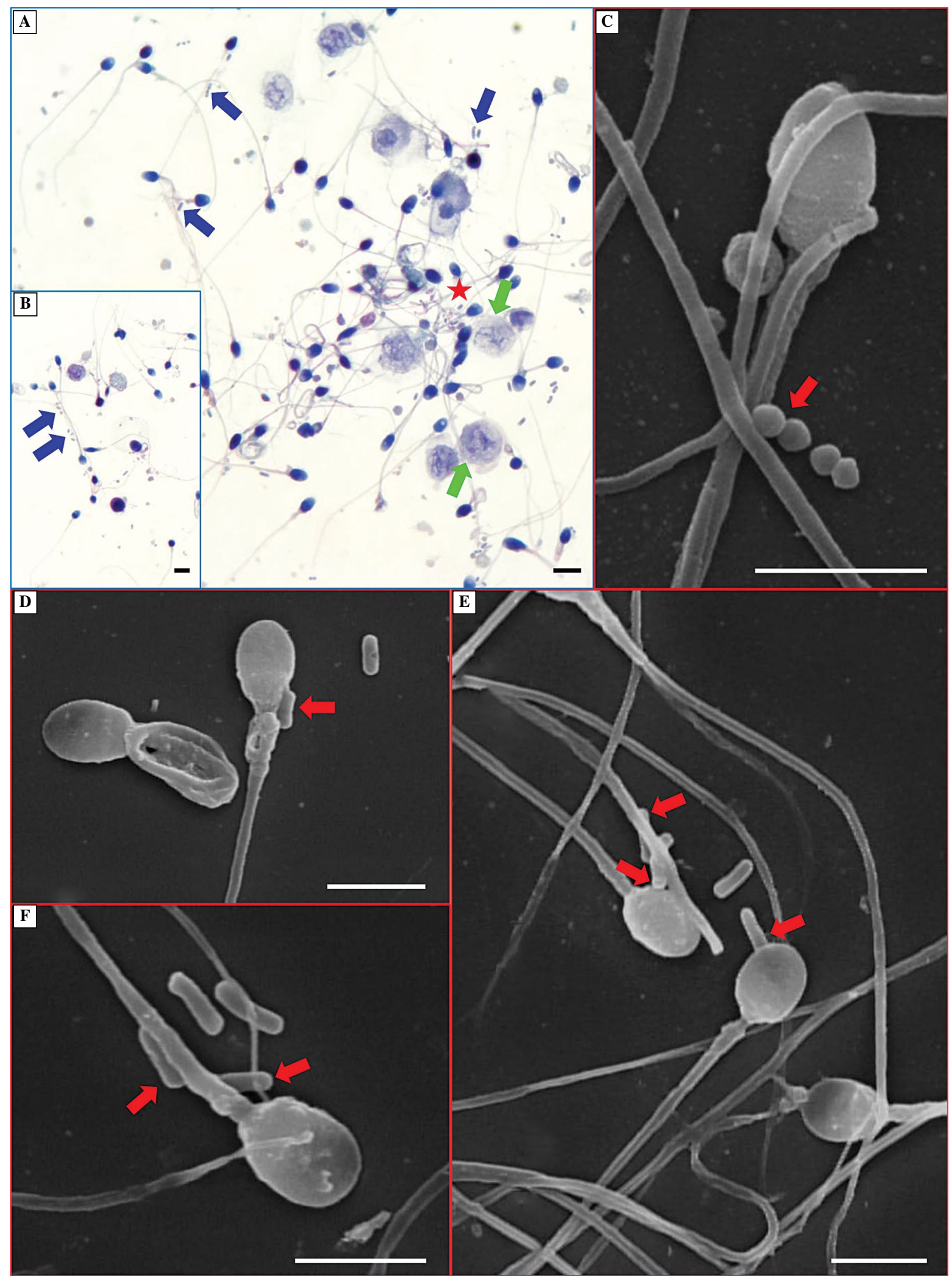

Figure 1. Interactions among bacteria, leukocytes and human spermatozoa. Papanicolaou-stained smear of human semen with bacteriospermia and leukocytospermia in situ. Sperm agglutination in the presence of bacteria (asterisk); adhesion of bacteria (blue arrows) and leukocytes (green arrows) to the sperm structures (A, B). Scanning electron micrographs of ejaculated human spermatozoa incubated with Bacteroides ureolyticus (C) or with Escherichia coli, serotype O75:HNT (D-F) in in vitro conditions. Adhesion of bacteria to sperm structures (red arrows). Scale bar: $5 \mu \mathrm{m}$. Photographs by Malgorzata Piasecka, Department of Histology and Developmental Biology, Pomeranian Medical University, Szczecin, Poland 
of sperm phagocytosis, and by extracellular structures related to extracellular traps that help to eliminate male gametes [39]. Furthermore, these processes of sperm elimination can occur in human semen in isolated leukocytospermia, as well as in leukocytospermia coexisting with bacteriospermia. In the latter condition, sperm phagocytosis and entrapment appear to be more aggressive, and they both may lead to a disturbance of the natural system controlling semen quality [39]. During semen bacterial infection, the engulfment of spermatozoa due to phagocytosis is accompanied by the formation of reactive oxygen and nitrogen species, proteases, and immune factors. In bacterial semen infection, the induction all of the inflammatory reactions in the seminal tract through the activation of neutrophils and macrophages may indirectly exert a deleterious effect on male fertility.

\section{Indirect effect of bacteria and leukocytes on sperm cells}

\section{Role of oxidative stress}

The role of reactive oxygen species (ROS) in sperm cell biology is beyond doubt. At low levels, ROS play a physiologically important role in sperm hyperactivation, capacitation, and acrosome reaction; at higher levels, they cause oxidative stress that limits the fertilizing potential of the male gametes as a result of peroxidative damage to cellular macromolecules [67]. Growing evidence indicates that the imbalance between ROS levels and total antioxidant capacity (TAC) in semen leads to disorders of male gametes (also visible in routine semen analysis), and may be associated with distinct pathologies in the male reproductive tract, including varicocele, leukocytospermia, cryptorchidism, idiopathic infertility, testicular cancer, and urogenital tract inflammation and infection [68]. The dominant external source of ROS (usually generated as part of the host response) in seminal plasma are neutrophils and macrophages. Indeed, leukocytospermic patients are characterized by oxidative stress. However, patients presenting peroxidase-positive leukocytes at concentrations below $1 \times 10^{6} \mathrm{~mL}^{-1}$ ejaculate also revealed seminal oxidative stress, reflected as high ROS levels or low fertility index (ROS-TAC score) [69, 70]. Moreover, seminal oxidative stress during bacterial prostatitis has also been found, regardless of leukocytospermia status [71]. Male accessory gland infections (MAGI) are closely related to oxidative stress as a result of leukocyte-derived ROS overproduction or reduced antioxidant potential [72-75]. Interestingly, some authors have postulated the existence of a relation- ship between the degree of oxidative stress and the extension of MAGI. Vicari et al. [76] found higher levels of seminal ROS in prostatovesiculitis than in prostatitis alone. However, the highest ROS production in semen was observed in prostatovesiculoepididymitis. Furthermore, the oxidative stress level in inflammatory semen can be related to the type of infecting, contaminating, or colonizing bacterial strain. It is well documented that bacteria themselves, due to their toxic metabolites and virulence factors, stimulate ROS production in leukocytes; in this context, they can also be a source of external ROS in bacterial semen infections [77]. For example, molecular mechanisms underlying LPS-induced ROS generation in macrophages are well recognized [78]. Both superoxide and hydrogen peroxide are metabolic products of $U$. urealyticum [79]. Indeed, abnormally elevated ROS levels in semen samples among prostatitis patients with positive $U$. urealyticum cultures have been shown [26]. It is known that $B$. urealyticus produces superoxide dismutase (SOD) that supplies additional amounts of hydrogen peroxide, which is the most toxic to sperm [80].

The detrimental effects of ROS on sperm function include alterations in both conventional and nonconventional sperm parameters. Patients with MAGI, especially when associated with $C$. trachomatis or $U$. urealyticum infection, often present significantly reduced sperm concentration, total sperm number, motile spermatozoa, or sperm with normal morpho$\operatorname{logy}[13,24]$. However, the degree of impaired semen quality seems to be directly related to the extension of MAGI [72]. Semen hyperviscosity turns out to be associated with increased oxidative stress in infertile patients with bacterial prostatitis, especially when the infection extends to the seminal vesicles [81]. Apart from the changes in sperm characteristics, seminal oxidative stress may be a cause of interaction with all sperm components, especially with polyunsaturated fatty acids, which are present in large amounts in sperm membranes. Sperm membrane lipid peroxidation status, measured by malondialdehyde (MDA) concentration, is the main nonconventional measurable marker of oxidative stress in semen. Malondialdehyde levels have often been correlated with deterioration of sperm quality [82-84]. An association between the presence of some known pathogens, such as $U$. urealyticum or C. trachomatis, and the induction of sperm lipid peroxidation, as judged by the MDA levels, has also been suggested [17, 26]. Moreover, there are suggestions that, in the presence of bacterial urogenital infections and varicocele, MDA might be considered a marker of altered sperm quality, and especially reduced sperm motility [85]. A recent 
study by our group supports evidence that, under in vitro conditions, some types of bacteria (both known pathogens and conditionally pathogenic types) may be important inducers of oxidative stress responsible for the destruction of sperm membranes, which in turn may lead to subfertility expressed as a reduction in penetrated oocytes in SPA. Additionally, our measurements have demonstrated that the harmful activity of bacterial agents towards spermatozoa do not require the mediation of leukocytes. However, these latter were additional mediators that worsened sperm fertilizing potential through peroxidative damage of sperm membranes [9]. Regardless of whether MDA may be a marker of semen infection or not, the process of lipid sperm membrane peroxidation is a crucial factor in the aetiology of defective sperm function during bacteriospermia and leukocytospermia.

Although seminal leukocytes have the potential to cause oxidative stress, the intrinsic ROS production of spermatozoa themselves also leads to oxidative damage in male gametes, once it exceeds the ability of intrinsic sperm enzymatic and nonenzymatic systems to its neutralization $[86,87]$. Some investigators have reported stronger relationships between intrinsic than extrinsic ROS production in semen and sperm DNA integrity [49]. The factors responsible for excessive ROS generation by spermatozoa are not entirely clear. Among them, age, environmental, and lifestyle factors are most frequently mentioned in the literature [88-91]. Interestingly, leukocytospermia has been shown to play a role in stimulating ROS production by the sperm themselves [58, 92]. The interactions between spermatozoa and leukocytes in the context of the oxidoreductive potential of ejaculated spermatozoa have also been studied by our group. Previously, we have demonstrated that ejaculates contain sperm populations that differ in oxidoreductive potential. This may influence their function and response to the surrounding environment [93]. In another study, the presence of bacteria was found to decrease the effective neutralization of leukocyte-derived ROS by sperm, depending on the type of bacterial strain and the sperm subpopulation used [80]. These are strong suggestions that inflammatory mediators, such as bacteria and leukocytes, are responsible for quantitative and qualitative changes in the oxygen metabolism of spermatozoa; this, in turn, determines the magnitude of the interaction between toxic oxygen metabolites and cell macromolecules with subsequent consequences for sperm fertilizing potential.

There is now increasing evidence that mitochondria are a major source of intracellular ROS in spermatozoa [94, 95]. One novel concept suggests that mitochondrial ROS generation may decide whether spermatozoon remains alive or enters an apoptotic state; its role in the aetiology of male infertility has most recently been postulated in the literature [96].

\section{Apoptosis/necrosis}

Apoptosis is a natural process that regulates sperm cell numbers through the stages of spermatogenesis, and is one of the principal mechanisms by which abnormal or dead spermatozoa are eliminated. However, the induction of an apoptotic process in ejaculated human sperm is still controversial. Several authors have suggested the involvement of sperm apoptosis in impaired men's fertility with consequences for reducing sperm fertilizing potential [97-99]. Mature spermatozoa have been reported to express distinct markers of early and late apoptosis-related cell damage, including the externalization of phosphatidylserine (PS) from the inner to the outer membrane, caspase activation, the loss of mitochondrial membrane potential $(\Delta \psi \mathrm{m})$, and DNA fragmentation [96]. According to a novel theory regarding apoptotic process in mature spermatozoa, the increase in the production of ROS by the mitochondria is one of the first signs of intrinsic apoptosis. Mitochondrial ROS generation is closely associated with the lipid sperm membrane peroxidation cascade that generates electrophilic lipid aldehydes. The latter form adducts with sperm proteins, and also with proteins of the mitochondrial electron transport chain, and triggers mitochondrial ROS production with a subsequent detrimental effect on sperm motility [96, 100]. At the same time, there occur other features of the apoptotic process, such as the externalization of PS and the activation of caspases. Finally, oxidative stress, as a result of the self-perpetuating cascade of mitochondrial ROS production and lipid peroxidation, culminates in DNA fragmentation and sperm death caused by hydrogen peroxide, which is known to readily diffuse through the membranes $[96,101]$.

The increase in the percentage of sperm with apoptotic phenotype has often been reported to be higher in ejaculates from subfertile and infertile men with clinical conditions associated with oxidative stress, including varicocele [102], idiopathic infertility [103], and urogenital tract inflammation and infection [104, 105]. During bacterial semen infection, changes in sperm apoptotic markers can be attributed to both leukocytes and bacteria. The direct relationship between seminal leukocytes and apoptotic sperm characteristics has been postulated in both leukocytospermic [59] and nonleukocytospermic patients [106]; and in both cases, the mediating role of phagocyte-generated ROS was strongly suggested $[72,107]$. The involvement of bacteria in the induction of apoptosis of ejaculated 
human sperm is the subject of intense research. There are strong premises that the direct contact of bacteria and their toxins with spermatozoa is an initial signal for germ cell death. This is evidenced by experimental reports in which different types of bacterial strains directly increased apoptotic features in ejaculated human spermatozoa, without the mediation of external ROS generated by leukocytes $[11,31]$. The proapoptotic effect of bacteria on sperm may mostly or at least partially be the consequence of bacterial endotoxins, including LPS, porins, and peptidoglycans via Toll-like receptors (TLR) 2 and 4, of which expression in the membranes of human spermatozoa has been demonstrated [108]. To date, there have been relatively few studies of the direct influence of individual bacterial strains infecting male urogenital tract on sperm apoptosis. In this context, the apoptosis-inducing mechanism of the well-known pathogenic species $C$. trachomatis and E. coli is best documented. The exposure of sperm to C. trachomatis LPS has been reported to cause an increase in the production of ROS and caspase-mediated sperm apoptosis, as a result of interaction of LPS with CD14 on the sperm surface [109]. Satta et al. [18] observed sperm PS externalization and DNA fragmentation during experimental $C$. trachomatis semen infection. Lastly, C. trachomatis infection of semen in vivo has been found to increase mitochondrial depolarization, as well as caspase-3 activation [15]. A significant reduction in $\Delta \psi \mathrm{m}$, viability, and motility was also observed after the incubation of sperm with E. coli and its soluble factors [7]. In another experimental study, the loss of sperm motility induced by the soluble products of $E$. coli was accompanied by the increased intrinsic mitochondrial generation of ROS and membrane lipid peroxidation [8]. In line with these findings, our original experimental data have demonstrated a direct role for conditionally pathogenic bacterial strains, S. haemolyticus and B. ureolyticus, in the induction of sperm apoptosis, as reflected by reductions in sperm motility, mitochondrial depolarization, lipid peroxidation, loss of sperm membrane asymmetry, PS externalization, and DNA fragmentation with subsequently reduced competence of sperm-oocyte fusion [9, 31]. All the above data have provided molecular evidence for the induction of sperm death by distinct bacterial agents (differing in pathogenicity and metabolism), partially due to intrinsic apoptotic cascade.

There are strong suggestions that apoptosis is induced by different types of bacteria. However, the origin of sperm DNA damage during bacteriospermia may be more complex. Our data have demonstrated that, during experimental semen infection in vitro, ejaculated human spermatozoa exhibited reduced viability visible in HOS tests and increased proportions of dead sperm [9]. However, DNA fragmentation was observed in both apoptotic and necrotic sperm, and the most part of the latter [31]. This is in agreement with the ultrastructural findings of Collodel et al. [110], who observed a high percentage of sperm with anomalies typical of apoptosis, as well as of necrosis, from individuals affected by urogenital bacterial infection, although the percentage of necrotic sperm was predominant in the majority of infected semen samples. Moreover, sperm apoptosis and necrosis were also induced under experimental high-ROS conditions [111]. These observations are supported by a recent report that showed a lack of correlation between ROS and DNA fragmentation in semen, as well as a correlation between sperm-damaged DNA and mitochondrial depolarization, suggesting that intrinsic mitochondrial-dependent apoptotic pathways might not have a major impact on sperm DNA fragmentation [112]. It should be mentioned, however, that low co-presence of DNA fragmentation, oxidative damage and apoptotic markers in live sperm have also been demonstrated recently [113]. There is no doubt that the bacterial infection of semen causes severe damage to ejaculated sperm that results in ROS-generated cell death, due to both apoptosis and necrosis. However, the mechanism underlying ROS-induced necrosis under inflammatory conditions is questionable. Future studies could explain whether bacterial semen infection causes sperm death due to the necrosis itself or by necrosis as the final step of the apoptotic process, as suggested by some authors [110].

With respect to the relationship between sperm apoptotic markers and the fertility potential of spermatozoa, the published data are still controversial. However, the vast majority of authors agree that the determination of apoptotic markers in spermatozoa, usually measured by flow cytometry, has better potential to predict fertility in clinical practice than conventional semen parameters. Some authors have shown that, among the apoptotic markers, DNA status is the best predictor of both natural [99] and assisted [114, 115] conception. In contrast to these studies, Zhang et al. [116] have suggested that two early apoptotic changes, such as PS externalization and decreased $\Delta \psi \mathrm{m}$, might be the best markers for diagnosing male infertility. Sperm with normal phospholipid asymmetry, characterized by a lack of PS externalization, has been demonstrated to have a superior ability to capacitate and a high capability of achieving full fertile potential estimated in a SPA assay $[97,117]$. These findings correspond with our recent study demonstrating numerous correlations between reduced penetration of hamster zona-free oocytes by 
human spermatozoa and an increase in the scrambling of the plasma membrane phospholipids, as measured by merocyanine 540 (M540) dye during experimental semen bacterial infection [9]. It should be emphasized that, in human spermatozoa, a loss of lipid asymmetry in the M540 test also reflects degenerative membrane modifications that occur during apoptotic events [118, 119]. In turn, other investigators have found a positive correlation between peroxidative lipid sperm membrane damage, as reflected by MDA levels, and sperm fertility index, calculated on the basis of the number of sperm free of structural defects, sperm necrosis, and apoptosis (visible in transmission electron microscopy) in a group of infertile men with urogenital tract infections [85]. Taking into consideration all these results, we can state that, although human sperm DNA is susceptible to damage as a result of bacterial semen infection, changes in lipid sperm membrane structures are critical for sperm fertilizing potential in this pathological condition. Moreover, this statement supports the general opinion postulated by some authors regarding the role of sperm DNA integrity as a predictor of the genetic quality of the embryo rather than of fertility $[120,121]$. However, further research is required in order to recommend the marker with the best prognostic power in clinical practice reflecting lipid sperm membrane damage during bacterial semen infection.

\section{Role of the immune/autoimmune reactions}

An interplay between the immune and reproductive systems is involved in the mechanism of sperm damage as a consequence of local inflammation or infection; the participation of immune factors including cytokines, chemokines, and growth factors must also be taken into account. The main source of immune factors in the male reproductive tract is the testes, where they are involved in the regulation of spermatogenesis and the maintenance of the privileged immunosuppressive status of gonads [122]. The local production of cytokines in the secondary sex glands, irrespective of spermatogenesis, has also been postulated [123-126]. The proinflammatory cytokines produced and released in large amounts by infiltrating leukocytes (such as macrophages, lymphocytes, monocytes, and dendritic cells) support host defence mechanisms in cases of local infection, but also participate in various pathophysiological reactions. Studies using experimental models of autoimmune orchitis have demonstrated that the complex network of proinflammatory cytokines, such as tumor necrosis factor (TNF)- $\alpha$, interferon (IFN)- $-\gamma$, and interleukins (IL)-6, IL-12, IL-17, and IL-23 play critical roles in inducing permeability of the blood-testis barrier and immature germ cell apoptosis, due to their direct effects on adherens and tight junction restructuring events [127-129]. Finally, these factors can be involved in the disruption of tolerance and the production of autoantibodies against germ cell antigens (ASA). Opinions about the relevance of ASA in semen, as measured by the mixed antiglobulin reaction (MAR) and immunobead tests in urogenital tract infections are divided. There are reports demonstrating a significantly higher ASA incidence in seminal plasma from patients with prostatitis and epididymitis, as compared with noninflammatory group [130,131]. In contrast to these studies, others suggested the lack of correlation between the presence of ASA and inflammation/infection in semen [132]. Probably, it may be connected with molecular similarities between different strains of bacteria and sperm antigens, as previously demonstrated [133]. Regardless of a clinical relevance of seminal ASA in the urogenital tract inflammations/infections, the mediating role of upregulated cytokines during orchitis and epididymo-orchitis, leading to the impairment of spermatogenesis and loss of tolerance, remains to be fully appreciated.

The modulating role of cytokines in inflammatory reactions due to the direct effect on pro-oxidative and antioxidative systems (to the advantage of the ROS) has been postulated by our group and other investigators [134-137]. In this context, cytokines may play a crucial role in the perpetuation of semen inflammation and infection, and for this reason these bioactive substances may constitute an important link between the inflammation or infection of the urogenital tract and infertility status [138]. The adverse effect of cytokines on sperm membrane properties might constitute one of the several mechanisms by which these immune factors interfere with sperm quality during semen bacterial infection. An increase in lipid sperm membrane peroxidation, as judged by MDA levels, has been demonstrated in the presence of some proinflammatory cytokines under both in situ $[139,140]$ and in vitro conditions following the incubation of sperm with human recombinant proinflammatory cytokines $[141,142]$. However, the harmful effect of cytokines on sperm membranes appears to be closely associated with the accompanying leukocytospermia. This has been confirmed by numerous reports that have documented correlations between seminal leukocyte count and proinflammatory cytokine concentrations [140, 143-148]. Also in our own in vitro observations, the peroxidative damage of sperm membrane lipids was markedly enhanced in the simultaneous presence of cytokines and leukocytes [149]. Most probably, oxidative stress during semen inflammation and infection is modulated by the levels of certain cytokines; 
even more, during leukocytospermia, the ROS and cytokines produced by the leukocytes cooperate with each other, provoking a destructive effect on sperm membranes.

The participation of cytokines in the induction of human ejaculated sperm apoptosis has also been suggested. Among the various inflammatory cytokines, TNF- $\alpha$, one of the major cytokines produced during inflammation and infection, is most often presented as the inducer of human sperm apoptosis. In a few experimental in vitro studies, this cytokine has been found to increase the percentage of ejaculated spermatozoa with PS externalization or DNA fragmentation [150, 151]. These observations are supported by the findings of Allam et al. [104], who detected a correlation between seminal TNF- $\alpha$ level and apoptotic sperm in ejaculates from men with chronic urogenital tract inflammations. The proapoptotic effect of TNF- $\alpha$ on mature sperm cells can be mediated through ROS and nitric oxide production [152-154]. Little is known about the proapoptotic properties of IL-6, a proinflammatory cytokine produced in large amounts during semen infection. In our experimental study, IL- 6 concomitantly applied with IL-8 was able to increase the DNA fragmentation of ejaculated human spermatozoa [155]. The effect of IL-6 most likely occurred through binding to its receptor, IL-6R alpha, of which presence has been reported in ejaculated human spermatozoa [156]. However, the hypothesis of IL-6 or IL-8 contribution to sperm apoptosis has not so far been confirmed in clinical studies. The influence of other proinflammatory cytokines, such as IL- $1 \beta$ and IL-18 on apoptosis via induction of the Fas/Fas ligand (FasL) system has been already documented in somatic cells $[157,158]$. Some authors have described the harmful effects of IL-18 on sperm concentration and motility in infertile men with urogenital tract infections $[159,160]$. Additionally, a combination of IL-18 with IL-12 was linked with a high sperm fragmentation index in an in vitro model of semen bacterial infection [155]. However, the mechanism by which these cytokines induce apoptosis in mature spermatozoa is not yet understood, and is currently under investigation.

In the case of bacterial urogenital tract infections, many cytokines have been demonstrated in elevated concentrations in semen $[135,161]$. The list of published articles indicating direct connections between various cytokine levels in seminal fluid and sperm quality is long [81, 162]. Most investigators have suggested that seminal cytokines are mostly associated with the presence of leukocytes [163-165]. Elevated cytokine presence in the semen has been also attributed to pathogens $[135,162,166]$. However, there are studies in which seminal pathogens have been found to have no influence on cytokine levels [167, $168]$. Among the various inflammatory cytokines, seminal IL- $1 \beta$, IL-6, and IL-18 have been proposed for the role of specific biomarkers discriminating between patients with or without MAGI [165, 169, 170]. Moreover, according to some clinicians, some cytokines can be a part of the evaluation of the host inflammatory response in patients with complicated MAGI, in order to identify subjects who require additional antioxidant administration after antimicrobial treatment [76]. In turn, the seminal chemokine IL-8 has been also suggested as one of the most reliable and predictive surrogate markers of prostatitis [171]. Undoubtedly, cytokines, chemokines, and growth factors are an essential part of the inflammatory effect caused by bacteria and leukocytes. The number of clinical studies on the significance of the detection of cytokines in seminal plasma, especially in the context of bacterial urogenital tract infection, continues to increase. Assuming that cytokines do not act in isolation, but rather as part of a network, we cannot exclude the possibility that the toxicity of one cytokine to spermatozoa can be increased in the presence of the other cytokines. Most probably, interactions among numerous immune factors can create specific micropatterns of cytokines in semen that could delineate the infectious entity responsible for male infertility. It appears that controlled prospective studies that include a large number of patients and analyse a wide range of cytokines are urgently required to answer the question of the applicability of these factors as potential biomarkers.

\section{Conclusions}

Bacterial infection of the male urogenital tract has been associated with subfertility and infertility. However, the mechanism by which it affects fertility is complex and multifactorial (Figure 2). Distinct inflammatory reactions within the male urogenital tract are inevitably connected to oxidative stress, being the sum of microenvironment and sperm intrinsic damage. The induction of sperm apoptosis contributes as an important pathogenic mechanism by which both bacteria and leukocytes can alter human spermatozoa. However, understanding of the nature of sperm-leukocyte interactions during male urogenital tract bacterial infection is not yet complete. Most probably, the monitoring of a complex network of molecular, biochemical, immunological, oxidative, and inflammatory parameters in semen may offer a chance to better understand the mechanisms leading to subfertility and infertility caused or complicated by microbial infection of the semen. The value of such observations would be significant, 


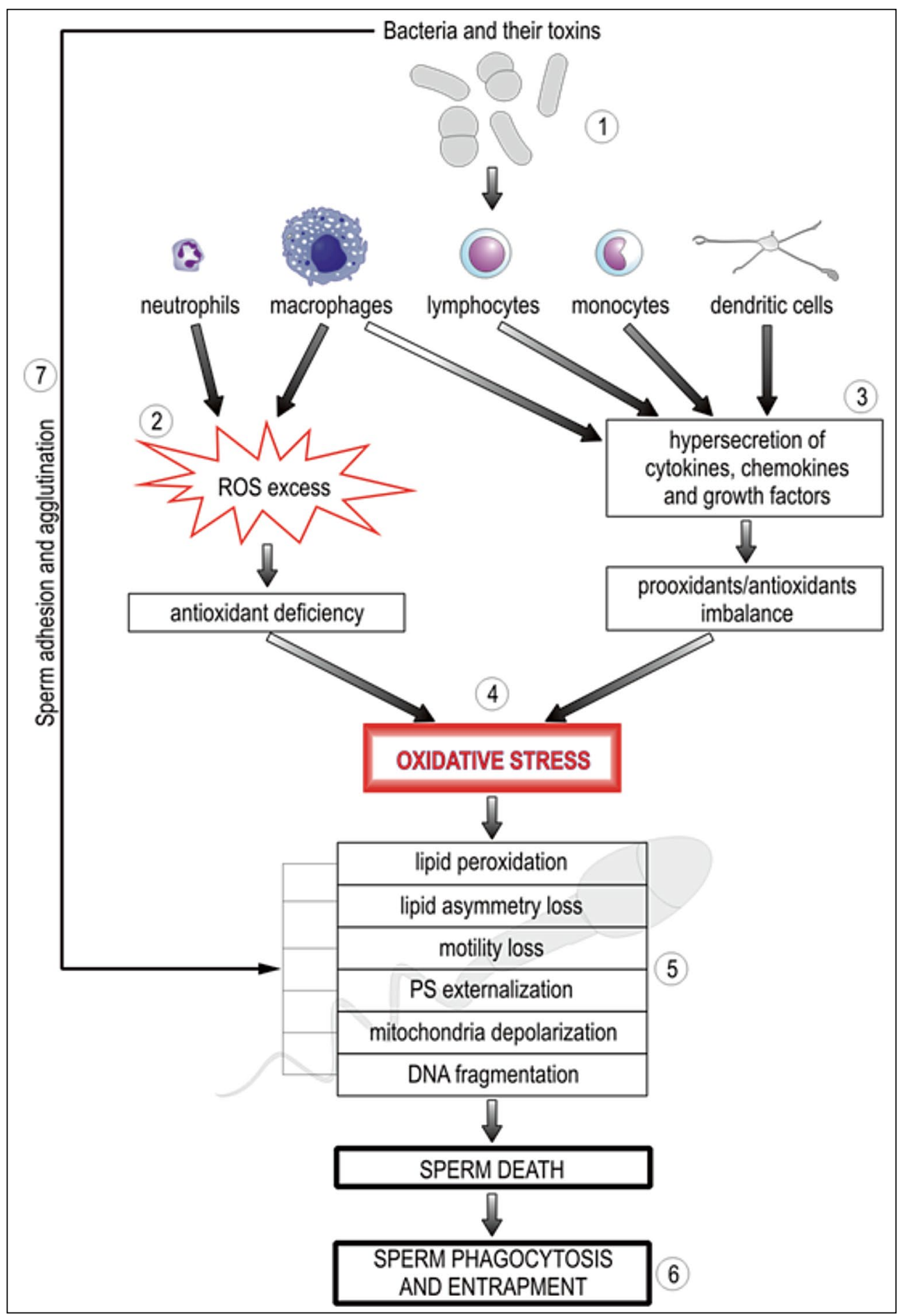

Figure 2. Proposed mechanisms of the harmful effect of bacterial semen infection on human spermatozoa. The diagram has been developed on the basis of our previously published results [9, 10, 31, 39, 51]. (1) Bacteria and their toxins trigger the infiltration of immune cells connected with (2) the production and release of large amounts of ROS (neutrophils, macrophages) as well as (3) immune regulatory factors (from macrophages, lymphocytes, monocytes, and dendritic cells); the cytokines may modulate the activities of the prooxidative and antioxidative systems, which may also result in the enhanced secretion of ROS; (4) When the amounts of ROS exceed the potential of the antioxidative defence, oxidative stress occurs; (5) Oxidative stress induces lipid sperm membrane peroxidation and leads to a series of detrimental defects in the spermatozoa, including lipid asymmetry loss, motility loss, PS externalization, and loss of $\Delta \Psi \mathrm{m}$. The changes culminate in DNA fragmentation and sperm death (apoptosis and necrosis); (6) Damaged and dead spermatozoa are eliminated by traditional phagocytosis and trapping mechanisms; (7) Bacteria kill sperm without the mediation of external ROS generated by leukocytes. Bacteria immobilize sperm and damage their morphology and function by tightly adhering to spermatozoa as well as by expressing surface virulence factors, and releasing soluble spermatotoxic factors. Modified from [162]. Abbreviations: ROS — reactive oxygen species; PS — phosphatidylserine 
and would support the development of new diagnostic platforms (biomarkers) for infertile males with semen infections, which are seen in a considerable number of men attempting both natural and assisted procreation. Key points:

- Sperm motility and phospholipid sperm membrane status are the most sensitive indicators of sperm damage during bacterial semen infection, which can be attributed to both bacteria and leukocytes.

- Bacteria and their toxins may be harmful to ejaculated spermatozoa independently of leukocyte contamination, although the concomitant presence of bacteria clearly enhances the harmful effects of leukocyte-generated oxidative stress by inducing the peroxidative damage of sperm membranes to a level above which their ability to penetrate and fuse with an oocyte may be significantly reduced.

- Induction of intrinsic apoptotic pathway could be an important pathomechanism by which both pathogenic and conditionally pathogenic bacteria can kill sperm cells. Extended semen microbiological diagnostics are recommended, especially in patients consulted for infertility and qualified for assisted reproduction techniques.

- Future research should be focused on the search for new seminal biomarkers for the noninvasive early diagnosis of asymptomatic urogenital tract infection.

\section{Acknowledgements}

This work was supported by Ministry of Science and Higher Education grant No. NN 407283539 and National Centre for Research and Development grant No. NR 13006606. The authors wish to thank Malgorzata Piasecka, Ph.D., for micrographs.

\section{References}

1. Fraczek M, Kurpisz M. Inflammatory mediators exert toxic effects of oxidative stress on human spermatozoa. J Androl. 2007;28:325-333. doi: 10.2164/jandrol.106.001149.

2. Sanocka-Maciejewska D, Ciupińska M, Kurpisz M. Bacterial infection and semen quality. J Reprod Immunol. 2005;67:51-56. PMID: 16112738 .

3. Isaiah IN, Nche BT, Nwagu IG, Nnanna II. Current studies on bacteriospermia the leading cause of male infertility: a protégé and potential threat towards means extinction. NAmJMed Sci. 2011;3:562-564. doi:10.4297/najms.2011.3559.

4. Huwe P, Diemer T, Ludwig M, Liu J, Schiefer HG, Weidner W. Influence of different uropathogenic microorganisms on human sperm motility parameters in an in vitro experiment. Andrologia. 1998;30:55-59. PMID: 9629444.

5. Köhn FM, Erdmann I, Oeda T, el-Mulla KF, Schiefer HG, Schill WB. Influence of urogenital infections on sperm functions. Andrologia. 1998;30:73-80. PMID: 9629446.

6. Diemer T, Huwe P, Ludwig M et al. Influence of autogenous leucocytes and Escherichia coli on sperm motility parameters in vitro. Andrologia. 2003;35:100-105. PMID: 12653783.
7. Schulz M, Sánchez R, Soto L, Risopatrón J, Villegas J. Effect of Escherichia coli and its soluble factors on mitochondrial membrane potential, phosphatidylserine translocation, viability, and motility of human spermatozoa. Fertil Steril. 2010;94:619-623. doi: 10.1016/j.fertnstert.2009.01.140.

8. Barbonetti A, Vassallo MR, Cinque B et al. Soluble products of Escherichia coli induce mitochondrial dysfunction-related sperm membrane lipid peroxidation which is prevented by lactobacilli. PLoS One. 2013;8:e83136. doi: 10.1371/journal. pone. 0083136 .

9. Fraczek M, Wiland E, Piasecka M et al. Fertilizing potential of ejaculated human spermatozoa during in vitro semen bacterial infection. Fertil Steril. 2014;102:711-719.e1. doi: 10.1016/j.fertnstert.2014.06.002.

10. Fraczek M, Piasecka M, Gaczarzewicz D et al. Membrane stability and mitochondrial activity of human-ejaculated spermatozoa during in vitro experimental infection with Escherichia coli, Staphylococcus haemolyticus and Bacteroides ureolyticus. Andrologia. 2012;44:315-329. doi: 10.1111/j.14390272.2012.01283.x.

11. Villegas J, Schulz M, Soto L, Sanchez R. Bacteria induce expression of apoptosis in human spermatozoa. Apoptosis. 2005;10:105-110. PMID: 15711926.

12. el-Mulla KF, Köhn FM, Dandal M et al. In vitro effect of Escherichia coli on human sperm acrosome reaction. Arch Androl. 1996;37:73-78. PMID: 8886254.

13. Mazzoli S, Cai T, Addonisio P, Bechi A, Mondaini N, Bartoletti R. Chlamydia trachomatis infection is related to poor semen quality in young prostatitis patients. Eur Urol. 2010;57:708-714. doi: 10.1016/j.eururo.2009.05.015.

14. Rybar R, Prinosilova P, Kopecka V et al. The effect of bacterial contamination of semen on sperm chromatin integrity and standard semen parameters in men from infertile couples. Andrologia. 2012;44:410-418. doi: 10.1111/j.14390272.2011.01198.x.

15. Sellami H, Znazen A, Sellami A et al. Molecular detection of Chlamydia trachomatis and other sexually transmitted bacteria in semen of male partners of infertile couples in Tunisia: the effect on semen parameters and spermatozoa apoptosis markers. PLoS One. 2014;9:e98903. doi: 10.1371/ journal.pone.0098903.

16. Kokab A, Akhondi MM, Sadeghi MR et al. Raised inflammatory markers in semen from men with asymptomatic chlamydial infection.J Androl. 2010;31:114-120. doi: 10.2164/ /jandrol.109.008300.

17. Segnini A, Camejo MI, Proverbio F. Chlamydia trachomatis and sperm lipid peroxidation in infertile men. Asian J Androl. 2003;5:47-49. PMID: 12647003.

18. Satta A, Stivala A, Garozzo A et al. Experimental Chlamydia trachomatis infection causes apoptosis in human sperm. Hum Reprod. 2006;21:134-137. PMID: 16126752.

19. Gallegos G, Ramos B, Santiso R, Goyanes V, Gosálvez J, Fernández JL. Sperm DNA fragmentation in infertile men with genitourinary infection by Chlamydia trachomatis and Mycoplasma. Fertil Steril. 2008;90:328-334. PMID: 17953955.

20. Wang Y, Liang CL, Wu JQ, Xu C, Qin SX, Gao ES. Do Ureaplasma urealyticum infections in the genital tract affect semen quality? Asian J Androl. 2006;8:562-568. PMID: 16752003.

21. De Francesco MA, Negrini R, Ravizzola G, Galli P, Manca N. Bacterial species present in the lower male genital tract: a five-year retrospective study. Eur J Contracept Reprod Health Care. 2011;16:47-53. doi: 10.3109/13625187.2010.533219.

22. Liu J, Wang Q, Ji X et al. Prevalence of Ureaplasma urealyticum, Mycoplasma hominis, Chlamydia trachomatis infec- 
tions, and semen quality in infertile and fertile men in China. Urology. 2014;83:795-799. doi: 10.1016/j.urology.2013.11.009.

23. Lee JS, Kim KT, Lee HS, Yang KM, Seo JT, Choe JH. Concordance of Ureaplasma urealyticum and Mycoplasma hominis in infertile couples: impact on semen parameters. Urology. 2013;81:1219-1224. doi: 10.1016/j.urology.2013.02.044.

24. Núñez-Calonge R, Caballero P, Redondo C, Baquero F, Martínez-Ferrer M, Meseguer MA. Ureaplasma urealyticum reduces motility and induces membrane alterations in human spermatozoa. Hum Reprod. 1998;13:2756-2761. PMID: 9804226.

25. Reichart M, Kahane I, Bartoov B. In vivo and in vitro impairment of human and ram sperm nuclear chromatin integrity by sexually transmitted Ureaplasma urealyticum infection. Biol Reprod. 2000;63:1041-1048. PMID: 10993825.

26. Potts JM, Sharma R, Pasqualotto F, Nelson D, Hall G, Agarwal A. Association of ureaplasma urealyticum with abnormal reactive oxygen species levels and absence of leukocytospermia. J Urol. 2000;163:1775-1778. PMID: 10799180.

27. Gdoura R, Kchaou W, Chaari C et al. Ureaplasma urealyticum, Ureaplasma parvum, Mycoplasma hominis and Mycoplasma genitalium infections and semen quality of infertile men. BMC Infect Dis. 2007;7:129. PMID: 17988404.

28. Mehta RH, Sridhar H, Vijay Kumar BR, Anand Kumar TC. High incidence of oligozoospermia and teratozoospermia in human semen infected with the aerobic bacterium Streptococcus faecalis. Reprod Biomed Online. 2002;5:17-21. PMID: 12470540.

29. Rodin DM, Larone D, Goldstein M. Relationship between semen cultures, leukospermia, and semen analysis in men undergoing fertility evaluation. Fertil Steril. 2003;79:1555-1558. PMID: 12801559.

30. Balmelli T, Stamm J, Dolina-Giudici M, Peduzzi R, Piffaretti-Yanez A, Balerna M. Bacteroides ureolyticus in men consulting for infertility. Andrologia. 1994;26:35-38. PMID: 8185059.

31. Fraczek M, Hryhorowicz M, Gaczarzewicz D et al. Can apoptosis and necrosis coexist in ejaculated human spermatozoa during in vitro semen bacterial infection? J Assist Reprod Genet. 2015; 32:771-779. doi: 10.1007/s10815-015-0462-x.

32. Cottell E, Harrison RF, McCaffrey M, Walsh T, Mallon E, Barry-Kinsella C. Are seminal fluid microorganisms of significance or merely contaminants? Fertil Steril. 2000;74:465-470. PMID: 10973639

33. Moretti E, Capitani S, Figura N et al. The presence of bacteria species in semen and sperm quality. J Assist Reprod Genet. 2009;26:47-56. doi: 10.1007/s10815-008-9283-5.

34. Monga M, Roberts JA. Spermagglutination by bacteria: receptor-specific interactions. J Androl. 1994;15:151-156. PMID: 7914518.

35. Kaur K, Prabha V. Sperm impairment by sperm agglutinating factor isolated from Escherichia coli: receptor specific interactions. Biomed Res Int. 2013;2013:548497. doi: $10.1155 / 2013 / 548497$.

36. Gallegos-Avila G, Ortega-Martínez M, Ramos-González B, Tijerina-Menchaca R, Ancer-Rodríguez J, Jaramillo-Rangel G. Ultrastructural findings in semen samples of infertile men infected with Chlamydia trachomatis and mycoplasmas. Fertil Steril. 2009;91:915-919. doi: 10.1016/j.fertnstert.2008.05.035.

37. Agarwal J, Srivastava S, Singh M. Pathogenomics of uropathogenic Escherichia coli. Indian J Med Microbiol. 2012;30:141-149. doi: 10.4103/0255-0857.96657.

38. Rudick CN, Berry RE, Johnson JR et al. Uropathogenic Escherichia coli induces chronic pelvic pain. Infect Immun. 2011;79:628-635. doi: 10.1128/IAI.00910-10.
39. Piasecka M, Fraczek M, Gaczarzewicz D et al. Novel morphological findings of human sperm removal by leukocytes in in vivo and in vitro conditions: preliminary study. Am J Reprod Immunol. 2014;72:348-358. doi: 10.1111/aji.12284.

40. Menkveld R. Leukocytospermia. In: Daya S, Harrison RF, Kempers RD, eds. Advances in Fertility and Reproductive Medicine. Amsterdam: Elsevier BV; 2004:218-224.

41. Menkveld R, Huwe P, Ludwig M, Weidner W. Morphological sperm alternations in different types of prostatitis. Andrologia. 2003;35:288-293. PMID: 14535857.

42. Weidner W, Pilatz A, Diemer T, Schuppe HC, Rusz A, Wagenlehner F. Male urogenital infections: impact of infection and inflammation on ejaculate parameters. World J Urol. 2013;31:717-723. doi: 10.1007/s00345-013-1082-7.

43. Haidl F, Haidl G, Oltermann I, Allam JP. Seminal parameters of chronic male genital inflammation are associated with disturbed sperm DNA integrity. Andrologia. 2015;47:464-469. doi: 10.1111 /and.12408.

44. Prabha V, Chaudhary N, Kaur S. Molecular mimicry between spermatozoa and bacteria. J Urol. 2011;186:2442-2447. doi: 10.1016/j.juro.2011.07.084.

45. Diemer T, Ludwig M, Huwe P, Hales DB, Weidner W. Influence of urogenital infection on sperm function. Curr Opin Urol. 2000;10:39-44. PMID: 10650514.

46. World Health Organization. WHO laboratory manual for the examination and processing of human semen. $5^{\text {th }}$ ed. Geneva: WHO Press; 2010.

47. Punab M, Lõivukene K, Kermes K, Mändar R. The limit of leucocytospermia from the microbiological viewpoint. Andrologia. 2003;35:271-278. PMID: 14535854.

48. Lackner J, Schatzl G, Horvath S, Kratzik C, Marberger M. Value of counting white blood cells (WBC) in semen samples to predict the presence of bacteria. Eur Urol. 2006;49:148-152. PMID: 16314032.

49. Henkel R, Kierspel E, Stalf T et al. Effect of reactive oxygen species produced by spermatozoa and leukocytes on sperm functions in non-leukocytospermic patients. Fertil Steril. 2005;83:635-642. PMID: 15749492.

50. Agarwal A, Mulgund A, Alshahrani S et al. Reactive oxygen species and sperm DNA damage in infertile men presenting with low level leukocytospermia. Reprod Biol Endocrinol. 2014;12:126. doi: 10.1186/1477-7827-12-126.

51. Sanocka D, Fraczek M, Jedrzejczak P, Szumała-Kakol A, Kurpisz M. Male genital tract infection: an influence of leukocytes and bacteria on semen. J Reprod Immunol. 2004;62:111-124. PMID: 15288187.

52. Tomlinson MJ, Barratt CL, Cooke ID. Prospective study of leukocytes and leukocyte subpopulations in semen suggests they are not a cause of male infertility. Fertil Steril. 1993;60:1069-1075. PMID: 8243688.

53. Aitken RJ, West K, Buckingham D. Leukocytic infiltration into the human ejaculate and its association with semen quality, oxidative stress, and sperm function. J Androl. 1994;15:343-352. PMID: 7982803.

54. Barraud-Lange V, Pont JC, Ziyyat A et al. Seminal leukocytes are Good Samaritans for spermatozoa. Fertil Steril. 2011;96:1315-1319. doi: 10.1016/i.fertnstert.2011.09.035.

55. Wolff H, Politch JA, Martinez A, Haimovici F, Hill JA, Anderson DJ. Leukocytospermia is associated with poor semen quality. Fertil Steril. 1990;53:528-536. PMID: 2407566.

56. Bezold G, Politch JA, Kiviat NB, Kuypers JM, Wolff H, Anderson DJ. Prevalence of sexually transmissible pathogens in semen from asymptomatic male infertility patients with and without leukocytospermia. Fertil Steril. 2007;87:1087-1097. PMID: 17433312. 
57. Kovalski NN, de Lamirande E, Gagnon C. Reactive oxygen species generated by human neutrophils inhibit sperm motility: protective effect of seminal plasma and scavengers. Fertil Steril. 1992;58:809-816. PMID: 1426329.

58. Saleh RA, Agarwal A, Kandirali E et al. Leukocytospermia is associated with increased reactive oxygen species production by human spermatozoa. Fertil Steril. 2002;78:1215-1224. PMID: 12477515.

59. Domes T, Lo KC, Grober ED, Mullen JB, Mazzulli T, Jarvi K. The incidence and effect of bacteriospermia and elevated seminal leukocytes on semen parameters. Fertil Steril. 2012;97:1050-1055. doi: 10.1016/j.fertnstert.2012.01.124.

60. Moretti E, Collodel G, Mazzi L, Campagna M, Iacoponi F, Figura N. Resistin, interleukin-6, tumor necrosis factor-alpha, and human semen parameters in the presence of leukocytospermia, smoking habit, and varicocele. Fertil Steril. 2014;102:354-360. doi: 10.1016/j.fertnstert.2014.04.017.

61. Lemkecher T, Dartigues S, Vaysse J et al. [Leucocytospermia, oxidative stress and male fertility: facts and hypotheses]. Gynecol Obstet Fertil. 2005;33:2-10. PMID: 15752659.

62. Piomboni P, Gambera L, Serafini F, Campanella G, Morgante G, De Leo V. Sperm quality improvement after natural anti-oxidant treatment of asthenoteratospermic men with leukocytospermia. Asian J Androl. 2008;10:201-206. PMID: 18097513.

63. Barraud-Lange V, Pont JC, Pocate K et al. Seminal leukocytes and clinical outcomes with donor sperm insemination. Fertil Steril. 2011;96:1320-1324.e1. doi: 10.1016/j.fertnstert.2011.08.025.

64. Cavagna M, Oliveira JB, Petersen CG et al. The influence of leukocytospermia on the outcomes of assisted reproductive technology. Reprod Biol Endocrinol. 2012;10:44. doi: 10.1186/1477-7827-10-44.

65. Pelliccione F, D'Angeli A, Cordeschi G et al. Seminal macrophages in ejaculates from men with couple infertility. Int $\mathrm{J} \mathrm{An-}$ drol. 2009;32:623-628. doi: 10.1111/j.1365-2605.2008.00909.x.

66. Tremellen K, Tunc O. Macrophage activity in semen is significantly correlated with sperm quality in infertile men. Int J Androl. 2010;33:823-831. doi: 10.1111/j.1365-2605.2009.01037.x.

67. Aitken RJ, Smith TB, Jobling MS, Baker MA, De Iuliis GN. Oxidative stress and male reproductive health. Asian J Androl. 2014;16:31-38. doi: 10.4103/1008-682X.122203.

68. Du Plessis SS, Agarwal A, Halabi J, Tvrda E. Contemporary evidence on the physiological role of reactive oxygen species in human sperm function. J Assist Reprod Genet. 2015;32:509-520. doi: $\underline{10.1007 / \mathrm{s} 10815-014-0425-7}$.

69. Sharma RK, Pasqualotto AE, Nelson DR, Thomas AJ Jr, Agarwal A. Relationship between seminal white blood cell counts and oxidative stress in men treated at an infertility clinic. J Androl. 2001;22:575-583. PMID: 11451354.

70. Agarwal A, Mulgund A, Alshahrani S et al. Reactive oxygen species and sperm DNA damage in infertile men presenting with low level leukocytospermia. Reprod Biol Endocrinol. 2014;12:126. doi: 10.1186/1477-7827-12-126.

71. Pasqualotto FF, Sharma RK, Potts JM, Nelson DR, Thomas AJ, Agarwal A. Seminal oxidative stress in patients with chronic prostatitis. Urology. 2000;55:881-885. PMID: 10840100.

72. Vicari E. Seminal leukocyte concentration and related specific reactive oxygen species production in patients with male accessory gland infections. Hum Reprod. 1999;14:2025-2030. PMID: 10438421

73. Shahed AR, Shoskes DA. Oxidative stress in prostatic fluid of patients with chronic pelvic pain syndrome: correlation with gram positive bacterial growth and treatment response. J Androl. 2000;21:669-675. PMID: 10975414.
74. Zhou JF, Xiao WQ, Zheng YC, Dong J, Zhang SM. Increased oxidative stress and oxidative damage associated with chronic bacterial prostatitis. Asian J Androl. 2006;8:317-323. PMID: 16625281.

75. Kullisaar T, Türk S, Punab M et al. Oxidative stress in leucocytospermic prostatitis patients: preliminary results. Andrologia. 2008;40:161-172. doi: 10.1111/j.1439-0272.2007.00816.x.

76. Vicari E, La Vignera S, Calogero AE. Oxidative stress and infection. In: Agarwal A, Aitken RJ, Alvarez JG, eds. Studies on Men Health and Fertility. New York: Humana Press; 2012:551-570.

77. Wang A, Fanning L, Anderson DJ, Loughlin KR. Generation of reactive oxygen species by leukocytes and sperm following exposure to urogenital tract infection. Arch Androl. 1997;39:11-17. PMID: 9202828.

78. Maitra U, Singh N, Gan L, Ringwood L, Li L. IRAK-1 contributes to lipopolysaccharide-induced reactive oxygen species generation in macrophages by inducing NOX-1 transcription and Rac1 activation and suppressing the expression of antioxidative enzymes.J Biol Chem. 2009;284:35403-35411. doi: $10.1074 /$ jbc.M109.059501.

79. Meier B, Habermehl GG. Evidence for superoxide dismutase and catalase in mollicutes and release of reactive oxygen species. Arch Biochem Biophys. 1990;277:74-79. PMID: 2154957.

80. Fraczek M, Szumala-Kakol A, Jedrzejczak P, Kamieniczna M, Kurpisz M. Bacteria trigger oxygen radical release and sperm lipid peroxidation in in vitro model of semen inflammation. Fertil Steril. 2007;88:1076-1085. PMID: 17383646.

81. Castiglione R, Salemi M, Vicari LO, Vicari E. Relationship of semen hyperviscosity with IL-6, TNF- $\alpha$, IL-10 and ROS production in seminal plasma of infertile patients with prostatitis and prostato-vesiculitis. Andrologia. 2014;46:1148-1155. doi: $10.1111 /$ and.12207.

82. Hsieh YY, Chang CC, Lin CS. Seminal malondialdehyde concentration but not glutathione peroxidase activity is negatively correlated with seminal concentration and motility. Int J Biol Sci. 2006;2:23-29. PMID: 16680200.

83. Shamsi MB, Venkatesh S, Kumar R et al. Antioxidant levels in blood and seminal plasma and their impact on sperm parameters in infertile men. Indian J Biochem Biophys. 2010;47:38-43. PMID: 21086753.

84. Atig F, Raffa M, Ali HB, Abdelhamid K, Saad A, Ajina M. Altered antioxidant status and increased lipid per-oxidation in seminal plasma of tunisian infertile men. Int J Biol Sci. 2012;8:139-149. PMID: 22211112.

85. Collodel G, Moretti E, Micheli L, Menchiari A, Moltoni L, Cerretani D. Semen characteristics and malondialdehyde levels in men with different reproductive problems. Andrology. 2015;3:280-286. doi: 10.1111/andr.297.

86. Koppers AJ, De Iuliis GN, Finnie JM, McLaughlin EA, Aitken RJ. Significance of mitochondrial reactive oxygen species in the generation of oxidative stress in spermatozoa.J Clin Endocrinol Metab. 2008;93:3199-3207. doi:10.1210//jc.2007-2616.

87. Henkel R, Bastiaan HS, Schüller S, Hoppe I, Starker W, Menkveld R. Leucocytes and intrinsic ROS production may be factors compromising sperm chromatin condensation status. Andrologia. 2010;42:69-75. doi: 10.1111/j. 1439-0272.2009.00967.x.

88. Wei YH, Kao SH, Lee HC. Simultaneous increase of mitochondrial DNA deletions and lipid peroxidation in human aging. Ann N Y Acad Sci. 1996;786:24-43. PMID: 8687024.

89. Kasahara E, Sato EF, Miyoshi M et al. Role of oxidative stress in germ cell apoptosis induced by di(2-ethylhexyl)phthalate. Biochem J. 2002;365:849-856. PMID: 11982482.

90. Saleh RA, Agarwal A, Sharma RK, Nelson DR, Thomas AJ Jr. Effect of cigarette smoking on levels of seminal oxidati- 
ve stress in infertile men: a prospective study. Fertil Steril. 2002;78:491-499. PMID: 12215323.

91. Cocuzza M, Athayde KS, Agarwal A et al. Age-related increase of reactive oxygen species in neat semen in healthy fertile men. Urology. 2008;71:490-494. doi: 10.1016/j.urology.2007.11.041.

92. Mupfiga C, Fisher D, Kruger T, Henkel R. The relationship between seminal leukocytes, oxidative status in the ejaculate, and apoptotic markers in human spermatozoa. Syst Biol Reprod Med. 2013;59:304-311. doi: 10.3109/19396368.2013.821540.

93. Fraczek M, Sanocka D, Kurpisz M. Interaction between leucocytes and human spermatozoa influencing reactive oxygen intermediates release. Int J Androl. 2004;27:69-75. PMID: 15149463.

94. Murphy MP. How mitochondria produce reactive oxygen species. Biochem J. 2009;417:1-13. doi: 10.1042/BJ20081386.

95. Amaral A, Lourenço B, Marques M, Ramalho-Santos J. Mitochondria functionality and sperm quality. Reproduction. 2013;146:R163-R174. doi: 10.1530/REP-13-0178.

96. Koppers AJ, Mitchell LA, Wang P, Lin M, Aitken RJ. Phosphoinositide 3-kinase signalling pathway involvement in a truncated apoptotic cascade associated with motility loss and oxidative DNA damage in human spermatozoa. Biochem J. 2011;436:687-698. doi: 10.1042/BJ20110114.

97. Said T, Agarwal A, Grunewald S et al. Selection of nonapoptotic spermatozoa as a new tool for enhancing assisted reproduction outcomes: an in vitro model. Biol Reprod. 2006;74:530-537. PMID: 16306419.

98. Roessner C, Paasch U, Kratzsch J, Glander HJ, Grunewald S. Sperm apoptosis signalling in diabetic men. Reprod Biomed Online. 2012;25:292-299. doi: 10.1016/j.rbmo.2012.06.004.

99. Zorn B, Golob B, Ihan A, Kopitar A, Kolbezen M. Apoptotic sperm biomarkers and their correlation with conventional sperm parameters and male fertility potential.J Assist Reprod Genet. 2012;29:357-364. doi: 10.1007/s10815-012-9718-x.

100. Aitken RJ, Whiting S, De Iuliis GN, McClymont S, Mitchell LA, Baker MA. Electrophilic aldehydes generated by sperm metabolism activate mitochondrial reactive oxygen species generation and apoptosis by targeting succinate dehydrogenase. J Biol Chem. 2012;287:33048-33060. PMID: 22851170.

101. Mitchell LA, De Iuliis GN, Aitken RJ. The TUNEL assay consistently underestimates DNA damage in human spermatozoa and is influenced by DNA compaction and cell vitality: development of an improved methodology. Int J Androl. 2011;34:2-13. doi: 10.1111/i.1365-2605.2009.01042.x.

102. Wu GJ, Chang FW, Lee SS, Cheng YY, Chen CH, Chen IC. Apoptosis-related phenotype of ejaculated spermatozoa in patients with varicocele. Fertil Steril. 2009;91:831-837. doi: 10.1016/j.fertnstert.2007.12.058.

103. Wang X, Sharma RK, Sikka SC, Thomas AJ Jr, Falcone T, Agarwal A. Oxidative stress is associated with increased apoptosis leading to spermatozoa DNA damage in patients with male factor infertility. Fertil Steril. 2003;80:531-535. PMID: 12969693.

104. Allam JP, Fronhoffs F, Fathy A et al. High percentage of apoptotic spermatozoa in ejaculates from men with chronic genital tract inflammation. Andrologia. 2008;40:329-334. doi: 10.1111/j.1439-0272.2008.00864.x.

105. La Vignera S, Condorelli R, D'Agata R, Vicari E, Calogero AE. Semen alterations and flow-citometry evaluation in patients with male accessory gland infections. $J$ Endocrinol Invest. 2012;35:219-223. doi: 10.3275/7924.

106. Zorn B, Ihan A, Kopitar AN, Kolbezen M, Sesek-Briski A, Meden-Vrtovec H. Changes in sperm apoptotic markers as related to seminal leukocytes and elastase. Reprod Biomed Online. 2010;21:84-92. doi: 10.1016/j.rbmo.2010.03.016.
107. Villegas J, Schulz M, Soto L, Iglesias T, Miska W, Sánchez R. Influence of reactive oxygen species produced by activated leukocytes at the level of apoptosis in mature human spermatozoa. Fertil Steril. 2005;83:808-810. PMID: 15749526.

108. Fujita Y, Mihara T, Okazaki T et al. Toll-like receptors (TLR) 2 and 4 on human sperm recognize bacterial endotoxins and mediate apoptosis. Hum Reprod. 2011;26:2799-2806. doi: 10.1093/humrep/der234.

109. Eley A, Hosseinzadeh S, Hakimi H, Geary I, Pacey AA. Apoptosis of ejaculated human sperm is induced by co-incubation with Chlamydia trachomatis lipopolysaccharide. Hum Reprod. 2005;20:2601-2607. PMID: 15905291.

110. Collodel G, Baccetti B, Capitani S, Moretti E. Necrosis in human spermatozoa. I. Ultrastructural features and FISH study in semen from patients with uro-genital infections. J Submicrosc Cytol Pathol. 2005;37:67-73. PMID: 16136729.

111. Mahfouz RZ, du Plessis SS, Aziz N, Sharma R, Sabanegh E, Agarwal A. Sperm viability, apoptosis, and intracellular reactive oxygen species levels in human spermatozoa before and after induction of oxidative stress. Fertil Steril. 2010;93:814-821. doi: 10.1016/j.fertnstert.2008.10.068.

112. Lobascio AM, De Felici M, Anibaldi M, Greco P, Minasi MG, Greco E. Involvement of seminal leukocytes, reactive oxygen species, and sperm mitochondrial membrane potential in the DNA damage of the human spermatozoa. Andrology. 2015;3:265-270. doi: 10.1111/andr.302.

113. Muratori M, Tamburrino L, Marchiani S et al. Investigation on the origin of sperm dna fragmentation: role of apoptosis, immaturity and oxidative stress. Mol Med. 2015;21:109-122. doi: 10.2119/molmed.2014.00158.

114. Larson KL, DeJonge CJ, Barnes AM, Jost LK, Evenson DP. Sperm chromatin structure assay parameters as predictors of failed pregnancy following assisted reproductive techniques. Hum Reprod. 2000;15:1717-1722. PMID: 10920092.

115. Boe-Hansen GB, Fedder J, Ersbøll AK, Christensen P. The sperm chromatin structure assay as a diagnostic tool in the human fertility clinic. Hum Reprod. 2006;21:1576-1582. PMID: 16543258.

116. Zhang HB, Lu SM, Ma CY, Wang L, Li X, Chen ZJ. Early apoptotic changes in human spermatozoa and their relationships with conventional semen parameters and sperm DNA fragmentation. Asian J Androl. 2008;10:227-235. PMID: 18097533

117. Grunewald S, Baumann T, Paasch U, Glander HJ. Capacitation and acrosome reaction in nonapoptotic human spermatozoa. Ann N Y Acad Sci. 2006;1090:138-146. PMID: 17384256.

118. Muratori M, Porazzi I, Luconi M, Marchiani S, Forti G, Baldi E. AnnexinV binding and merocyanine staining fail to detect human sperm capacitation. J Androl. 2004;25:797-810. PMID: 15292113.

119. Martin G, Sabido O, Durand P, Levy R. Phosphatidylserine externalization in human sperm induced by calcium ionophore A23187: relationship with apoptosis, membrane scrambling and the acrosome reaction. Hum Reprod. 2005;20:3459-3468. PMID: 16113043.

120. Cosci I, Moretti E, Collodel G. Lipid peroxidation in human spermatozoa from men with genitourinary infections. Syst Biol Reprod Med. 2008;54:75-83. doi: 10.1080/19396360801947722.

121. Aitken RJ, Bronson R, Smith TB, De Iuliis GN. The source and significance of DNA damage in human spermatozoa; a commentary on diagnostic strategies and straw man fallacies. Mol Hum Reprod. 2013;19:475-485. doi: 10.1093/molehr/gat025.

122. Cudicini, C, Kercret H, Touzalin AM, Ballet F, Jégou B. Vectorial production of interleukin 1 and interleukin 6 by rat 
Sertoli cells cultured in a dual culture compartment system. Endocrinology. 1997;138:2863-7280. PMID: 9202229.

123. Huleihel M, Lunenfeld E. Regulation of spermatogenesis by paracrine/autocrine testicular factors. Asian J Androl. 2004;6:259-268. PMID: 15273877.

124. Matalliotakis I, Kiriakou D, Fragouli I, Sifakis S, Eliopoulos G, Koumantakis E. Interleukin-6 in seminal plasma of fertile and infertile men. Arch Androl. 1998;41:43-50. PMID: 9642460 .

125. Friebe K, Bohring C, Skrzypek J, Krause W. Levels of interleukin-6 and interleukin-8 in seminal fluid of men attending an andrological clinic. Andrologia. 2003;35:126-129. PMID: 12653788

126. Seshadri S, Bates M, Vince G, Jones DI. The role of cytokine expression in different subgroups of subfertile men. Am J Reprod Immunol. 2009;62:275-282. doi: 10.1111/j. 1600-0897.2009.00736.x.

127. Jacobo P, Guazzone VA, Theas MS, Lustig L. Testicular autoimmunity. Autoimmun Rev. 2011;10:201-204. doi: 10.1016/j. autrev.2010.09.026.

128. Naito M, Terayama H, Hirai S, Qu N, Lustig L, Itoh M. Experimental autoimmune orchitis as a model of immunological male infertility. Med Mol Morphol. 2012;45:185-189. doi: 10.1007/s00795-012-0587-2.

129. Qu N, Xu M, Mizoguchi I, Furusawa J, Kaneko K, Watanabe K. Pivotal roles of T-helper 17-related cytokines, IL-17, IL-22, and IL-23, in inflammatory diseases. Clin Dev Immunol. 2013;2013:968549. doi: 10.1155/2013/968549.

130. Bates CA. Antisperm antibodies and male subfertility. $\mathrm{Br}$ J Urol. 1997;80:691-697. PMID: 9393288.

131. Dimitrova D, Kalaydjiev S, Hristov L, Nikolov K, Boyadjiev T, Nakov L. Antichlamydial and antisperm antibodies in patients with chlamydial infections. Am J Reprod Immunol. 2004;52:330-336. PMID: 15550070.

132. Marconi M, Nowotny A, Pantke P, Diemer T, Weidner W. Antisperm antibodies detected by mixed agglutination reaction and immunobead test are not associated with chronic inflammation and infection of the seminal tract. Andrologia. 2008;40:227-234. doi: 10.1111/j.1439-0272.2008.00848.x.

133. Kurpisz M, Alexander NJ. Carbohydrate moieties on sperm surface: physiological relevance. Fertil Steril. 1995;63:158-165. PMID: 7528691.

134. Rajasekaran M, Hellstrom WJ, Naz RK, Sikka SC. Oxidative stress and interleukins in seminal plasma during leukocytospermia. Fertil Steril. 1995;64:166-171. PMID: 7789553.

135. Omu AE, Al-Qattan F, Al-Abdul-Hadi FM, Fatinikun MT, Fernandes S. Seminal immune response in infertile men with leukocytospermia: effect on antioxidant activity. Eur J Obstet Gynecol Reprod Biol. 1999;86:195-202. PMID: 10509791.

136. Sanocka D, Jedrzejczak P, Szumała-Kakol A, Fraczek M, Kurpisz M. Male genital tract inflammation: The role of selected interleukins in regulation of pro-oxidant and antioxidant enzymatic substances in seminal plasma. J Androl. 2003;24:448-455. PMID: 12721221.

137. Lanzafame FM, La Vignera S, Vicari E, Calogero AE. Oxidative stress and medical antioxidant treatment in male infertility. Reprod Biomed Online. 2009;19:638-659. PMID: 20021713.

138. Fraczek M, Kurpisz M. Cytokines in the male reproductive tract and their role in infertility disorders. J Reprod Immunol. 2015;108:98-104. doi: 10.1016/j.jri.2015.02.001.

139. Camejo MI, Segnini A, Proverbio F. Interleukin-6 (IL-6) in seminal plasma of infertile men, and lipid peroxidation of their sperm. Arch Androl. 2001;47:97-101. PMID: 11554690 .
140. Liu J, Wang YX, Wu YL, Qian XM, Xiang ZQ. [Measurement of the reactive oxygen species and cytokines in the seminal plasma of leukocytospermic patients]. Zhonghua Nan Ke Xue. 2003;9:103-105. PMID: 12749127.

141. Buch JP, Kolon TF, Maulik N, Kreutzer DL, Das DK. Cytokines stimulate lipid membrane peroxidation of human sperm. Fertil Steril. 1994;62:186-188. PMID: 8005288.

142. Martínez P, Proverbio F, Camejo MI. Sperm lipid peroxidation and pro-inflammatory cytokines. Asian J Androl. 2007;9:102-107. PMID: 17187161.

143. Shimoya K, Matsuzaki N, Tsutsui T, Taniguchi T, Saji F, Tanizawa O. Detection of interleukin-8 (IL-8) in seminal plasma and elevated IL-8 in seminal plasma of infertile patients with leukospermia. Fertil Steril. 1993;59:885-888. PMID: 8458511.

144. Eggert-Kruse W, Boit R, Rohr G, Aufenanger J, Hund M, Strowitzki T. Relationship of seminal plasma interleukin (IL) -8 and IL-6 with semen quality. Hum Reprod. 2001;16:517-528. PMID: 11228223.

145. Jedrzejczak P, Fraczek M, Szumała-Kakol A, Taszarek-Hauke G, Pawelczyk L, Kurpisz M. Consequences of semen inflammation and lipid peroxidation on fertilization capacity of spermatozoa in in vitro conditions. Int $J$ Androl. 2005;28:275-283. PMID: 16128987.

146. Kopa Z, Wenzel J, Papp GK, Haidl G. Role of granulocyte elastase and interleukin-6 in the diagnosis of male genital tract inflammation. Andrologia. 2005;37:188-194. PMID: 16266398.

147. Politch JA, Tucker L, Bowman FP, Anderson DJ. Concentrations and significance of cytokines and other immunologic factors in semen of healthy fertile men. Hum Reprod. 2007;22:2928-2935. PMID: 17855405.

148. Lotti F, Corona G, Mancini M et al. Ultrasonographic and clinical correlates of seminal plasma interleukin-8 levels in patients attending an andrology clinic for infertility. Int J Androl. 2011;34:600-613. doi: 10.1111/j.1365-2605.2010.01121.x.

149. Fraczek M, Sanocka D, Kamieniczna M, Kurpisz M. Proinflammatory cytokines as an intermediate factor enhancing lipid sperm membrane peroxidation in in vitro conditions. J Androl. 2008;29:85-92. PMID: 17804865.

150. Said TM, Agarwal A, Falcone T, Sharma RK, Bedaiwy MA, $\mathrm{Li} \mathrm{L}$. Infliximab may reverse the toxic effects induced by tumor necrosis factor alpha in human spermatozoa: an in vitro model. Fertil Steril. 2005;83:1665-1673. PMID: 15950634.

151. Perdichizzi A, Nicoletti F, La Vignera S et al. Effects of tumour necrosis factor-alpha on human sperm motility and apoptosis. J Clin Immunol. 2007;27:152-162. PMID: 17308869.

152. Barroso G, Morshedi M, Oehninger S. Analysis of DNA fragmentation, plasma membrane translocation of phosphatidylserine and oxidative stress in human spermatozoa. Hum Reprod. 2000;15:1338-1344. PMID: 10831565.

153. Ollero M, Gil-Guzman E, Lopez MC et al. Characterization of subsets of human spermatozoa at different stages of maturation: implications in the diagnosis and treatment of male infertility. Hum Reprod. 2001;16:1912-1921. PMID: 11527898.

154. Lampiao F, du Plessis SS. TNF-alpha and IL-6 affect human sperm function by elevating nitric oxide production. Reprod Biomed Online. 2008;17:628-631. PMID: 18983746.

155. Fraczek M, Szumala-Kakol A, Dworacki G, Sanocka D, Kurpisz M. In vitro reconstruction of inflammatory reaction in human semen: effect on sperm DNA fragmentation.J Reprod Immunol. 2013;100:76-85. PMID: 24344359.

156. Laflamme J, Akoum A, Leclerc P. Induction of human sperm capacitation and protein tyrosine phosphorylation by endometrial cells and interleukin-6. Mol Hum Reprod. 2005;11:141-150. PMID: 15665187. 
157. Dinarello CA. Interleukin-18, a proinflammatory cytokine. Eur Cytokine Netw. 2000;11:483-486. PMID: 11203186.

158. Feldmann M, Saklatvala J. Proinflammatory cytokines. In: Oppenheim JJ, Feldman M, eds. Cytokine reference. New York: Academic Press; 2001:291-305.

159. Matalliotakis IM, Cakmak H, Fragouli Y, Kourtis A, Arici A, Huszar G. Increased IL-18 levels in seminal plasma of infertile men with genital tract infections. Am J Reprod Immunol. 2006;55:428-433. PMID: 16674600.

160. Qian L, Zhou Y, Du C, Wen J, Teng S, Teng Z. IL-18 levels in the semen of male infertility: semen analysis. Int J Biol Macromol. 2014;64:190-192. doi: 10.1016/j.ijbiomac.2013.12.005.

161. Martinez-Prado E, Camejo Bermudez MI. Expression of IL-6, IL-8, TNF-alpha, IL-10, HSP-60, anti-HSP-60 antibodies, and anti-sperm antibodies, in semen of men with leukocytes and/or bacteria. Am J Reprod Immunol. 2010;63:233-243. doi: 10.1111/j.1600-0897.2009.00786.x.

162. Fraczek M, Czernikiewicz A, Kurpisz M. Cytokines and oxidative stress in germ line. In: Agarwal A, Aitken RJ, Alvarez JG, eds. Studies on Men Health and Fertility. New York: Humana Press; 2012:179-205.

163. Papadimas J, Goulis DG, Sotiriades A et al. Interleukin- 1 beta and tumor necrosis factor-alpha in normal/infertile men. Arch Androl. 2002;48:107-113. PMID: 11868623.

164. Krause W. Male accessory gland infection. Andrologia. 2008;40:113-116. doi: 10.1111/j.1439-0272.2007.00822.x.

165. Dziadecki W, Celińska A, Fracki S, Bablok L, Barcz E. Interleukin $1 \beta$ and interleukin 18 and their connection with leukocytospermia in human semen. Centr Eur J Immunol. 2010;35:157-161.

166. Mazzoli S, Cai T, Rupealta V et al. Interleukin 8 and anti-chlamydia trachomatis mucosal IgA as urogenital immunologic markers in patients with C. trachomatis prostatic infection. Eur Urol. 2007;51:1385-1393. PMID: 17107749.

167. Pannekoek Y, Trum JW, Bleker OP, van der Veen F, Spanjaard L, Dankert J. Cytokine concentrations in seminal plasma from subfertile men are not indicative of the presence of Ureaplasma urealyticum or Mycoplasma hominis in the lower genital tract. J Med Microbiol. 2000;49:697-700. PMID: 10933253.

168. Aghazarian A, Stancik I, Pflüger H, Lackner J. Influence of pathogens and moderate leukocytes on seminal interleukin (IL)-6, IL-8, and sperm parameters. Int Urol Nephrol. 2013;45:359-365. doi: 10.1007/s11255-013-0400-8.

169. Depuydt CE, Bosmans E, Zalata A, Schoonjans F, Comhaire $\mathrm{FH}$. The relation between reactive oxygen species and cytokines in andrological patients with or without male accessory gland infection. J Androl. 1996;17:699-707. PMID: 9016401.

170. Koçak I, Yenisey C, Dündar M, Okyay P, Serter M. Relationship between seminal plasma interleukin- 6 and tumor necrosis factor alpha levels with semen parameters in fertile and infertile men. Urol Res. 2002;30:263-267. PMID: 12202945.

171. Lotti F, Maggi M. Interleukin 8 and the male genital tract. J Reprod Immunol. 2013;100:54-65. doi: 10.1016/i. jiri.2013.02.004. 